\title{
ANALYSIS OF AXIAL FORCES OF HEAVY-DUTY HARMONIC GEAR DRIVE
}

\author{
V N Strelnikov \\ Department of theoretical mechanics, \\ Belgorod state university of technology (BSUT), \\ Belgorod, Russia, \\ 308012, Belgorod, Kostyukov street 46. \\ E-mail: viktor.strelnickov2017@yandex.ru
}

\author{
M G Sukov \\ Private Joint Stock Company \\ Novokramatorsky mashinostroitelny zavod \\ Ukraine, Donetsk region, \\ 84305, Kramatorsk, Ordzhonikidze street 5. \\ E-mail: maxgs@yandex.ua
}

\begin{abstract}
The results of the theoretical investigations and simultaneous strain gauge measurements of axial forces in the flexspline and wave generator of heavy-duty harmonic gear drives, mobile hot-metal mixer and ore-pulverizing mill drives are presented. Comparative analysis of measurements and the theoretically computed data made it possible to establish satisfactory coincidence of the results obtained experimentally with
\end{abstract}

Keywords-axial force; flexspline; wave generator; strain gauge measurements; mixer; mill

\section{INTRODUCTION}

External loads through transmissions are concentrated on the mechanical drive that should not only withstand them successfully but also provide reliability of the machines performances. The mechanical drive while making $20-25 \%$ of the weight is the main cause of failures of mining and metallurgical equipment (up to 60\%). Breakthrough technologies such as harmonic gear drives distinguished by their high load-carrying capacities and solid performances serve as the reserve of increasing the level of the mechanical drive. Considerable advances are made in the analysis of the geometry, kinematics and strength of batch-produced small harmonic gear drives; there is a great progress in the field of their production [1].

The introduction of heavy-duty harmonic gear drives in heavy engineering industry is impeded by the influence of the size factor, which does not allow transferring the existing computing techniques to the large prototypes. In the available solutions, the functional connection of force and energy processes with elastic strain of the flexspline is not realized [2 - 4]. Physics of the phenomena proceeding in the elastic kinematic pair, disk - flexspline, is not revealed; the nature of axial forces in the field of the wave generator under load is not determined that decline the performances, limit the loadcarrying capacity and retard the development of the heavyduty harmonic gear drives $[5,6]$.

Studies in the force factors of interaction between elements of kinematic pairs of higher degree and elastic linkages aimed at increasing the load capacity and improving the performances of the heavy-duty harmonic gear drives are of scientific and practical interest for heavy engineering industry.

\section{WAVE GENERATOR — FLEXSPLINE INTERACTION ANALYSIS}

Heavy-duty harmonic gear drives have the disk-type wave generator, wide gear rings and teeth with the comparatively low module, of the order of $m=(1 \ldots 2) \mathrm{mm}$, that violates the theoretically based meshing conditions [7, 8], activates the conditions for meshing interference occurrence under high loads. The analytical model is developed which adequately simulates the interaction between the wave generator disks and the flexspline. While constructing the mathematical model the condition is assumed that radial load in the gearing is parabolically distributed and transferred to the disks without change. Maximum value of radial load $q_{\text {rmax }}$ is shifted from the major axis of the generator by the angle $\chi$ in the direction of the ingoing wave of the flexspline that is in line with the sense of rotation of the wave generator. Distribution of load $q_{r}$ in the contact zones of disks and the flexspline in the prototype is in agreement with the results obtained through strain gauging the circular spline tooth.

During wave motion of the cone-shapely deformed flexspline, in the zones of its contact with the disks axial frictional forces $q_{f}$ develop that are divided by the wave generator major axis into mutually contradirectional areas of forces $q_{f 1}, q_{f 2}$. Moment of friction $M$ induced by forces $q_{f 1}, q_{f 2}$, orients the disks in the direction perpendicular to the motion rotating them through some angle $\gamma$, restrained by the limits of mounting clearances. In this case mating of the disks with the flexspline represents some similarity of friction screw pairs with the lead angle of $\gamma$. Moreover, the rotation of the disks is oriented so that independently of the rotation sense of the wave generator shaft the latter is always "screwed" in the cone-shapely formed flexspline. Such similarity of the screw pairs adversely affects the harmonic gear drive operation. Supplementary energy losses arise and axial force of the shock nature is formed at the cost of inertial forces of the wave generator with heavy weight. The generator disks deform the flexspline located at the free end of the cylindrical shell the opposite end of which is installed on the driven shaft and fastened through the spline joint. On the arc of the disk contact with the flexspline $C D$ the radial forces $q_{r}$ act. Let us approximate them through parabolic relation: 


$$
q_{r}=q_{r \max }\left(1-\frac{\theta^{2}}{\theta^{* 2}}\right)
$$

where $\theta^{*}$ is the angular coordinate determining the length of radial load relative to its minimum value $q_{r \text { max }}$.

Radial load $q_{r}$ (1) forms strain of the flexspline and balances the radial components of the forces developed in the gearing that are taken up by the wave generator disks. This is determined by the radial float of the flexspline the forces to form which with the absence of the external load $\left(M_{2}=0\right)$ are low as compared with the radial forces in the gearing. Maximum value of the radial load $q_{\text {rmax }}$ is connected with the loading torque $M_{2}$ through the relation

$$
\begin{gathered}
M_{2}=\frac{d^{2}}{\operatorname{tg} \alpha} \cdot \int_{0}^{\theta^{*}} q_{r} d \theta, \\
q_{r_{\max }}=\frac{3 M_{2} \operatorname{tg} \alpha}{2 d^{2} \theta^{*}},
\end{gathered}
$$

where $d$ - circle diameter at the midpoint of the tooth of the circular spline.

Maximum value of the radial load $q_{r_{\max }}$ (3) is deviated relative to the wave generator major axis $O A$ for the angle $\chi$. Angle $\psi$ of deviation of the shell generatrix $B B_{1}$ relative to the unstrained state of the flexspline $K B_{I}$ is increased to the maximum value $\psi_{\max }$ at the axis $O A$, whereafter it reduces. This increases the length of generatrices $B B_{1}$ in front of axis $O A$ and reduces it behind the axis $O A$, that at constancy of the distance $l$ from the disk plane to the shell end causes axial slip of the disk relative to the flexspline. Arising frictional forces $q_{f}$ are proportional to the radial load $q_{r}$ and are directed parallel with the common axis of the harmonic gear drive. The resultants of frictional forces $F_{1}$ and $F_{2}$, are determined by integrating the torque $M_{2}$ from the equation (2)

$$
\begin{aligned}
& F_{1}=f q_{r \max } \alpha \cdot\left\{\frac{2}{3} \theta^{*}+\chi\left(1-\frac{\chi^{2}}{3 \theta^{2}}\right)\right\}, \\
& F_{2}=f q_{r \max } \alpha \cdot\left\{\frac{2}{3} \theta^{*}-\chi\left(1-\frac{\chi^{2}}{3 \theta^{2}}\right)\right\},
\end{aligned}
$$

where $a$ - distance between the drive center line and the surface of the disk contact with the flexspline.

Moment of friction $q_{f}$

$$
M=F_{1} x_{c 1}+F_{2} x_{c 2},
$$

where abscissae $x_{c 1}$ and $x_{c 2}$ of points of frictional forces application $F_{1}, F_{2}$

$$
\begin{aligned}
& x_{c_{1}}=\frac{3 a\left\{\left(2+\theta^{* 2}-\chi^{2}\right)-2\left[\cos \left(\theta^{*}+\chi\right)+\theta^{*} \sin \left(\theta^{*}+\chi\right)\right]\right\}}{2 \theta^{* 3}+\chi\left(3 \theta^{* 2}-\chi^{2}\right)}(7) \\
& x_{c_{2}}=\frac{3 a\left\{\left(2+\theta^{* 2}-\chi^{2}\right)-2\left[\cos \left(\theta^{*}-\chi\right)+\theta^{*} \sin \left(\theta^{*}-\chi\right)\right]\right\}}{2 \theta^{* 3}-\chi\left(3 \theta^{* 2}-\chi^{2}\right)} \text { (8) }
\end{aligned}
$$

The moment of friction $M(6)$ is determined by the substitution of values (3) - (5), (7), (8). It causes skewing of the disks with turn around the axis $O A$ through the angle $\gamma$, the value of which depends on the type of bearings and mounting clearances. The disks can be supported in radial double-row spherical roller bearings that allow for skewing, whereby the axial clearances between the disks are taken up and their end planes coincide. The disks form with the flexspline the frictional pair with the angle $\gamma$ equivalent to the lead angle. Angle $\gamma$ is connected with the total axial clearance of disks $\Delta$

$$
\Delta=\left(c_{1}+c_{2}\right)\left(\cos \gamma-\cos ^{2} \gamma\right)+\varepsilon \operatorname{tg} \gamma
$$

where $c_{1}, c_{2}$ are distances from the centers of the spherical bearings to the end planes of the disks divided by clearance $\Delta$, determined by the expression (9);

$\varepsilon$ - disks eccentricity.

Discs slip velocity $V_{f}$ and power of enegy losses $N_{f}$ in the zones of the disks contact with the flexspline are proportional to angle $\gamma$

$$
\begin{aligned}
& V_{f}=a \cdot \omega_{1} \cdot \operatorname{tg} \gamma, \\
& N_{f}=2\left(F_{l}+F_{2}\right) V_{f} .
\end{aligned}
$$

Axial force $F$ induced by the wave generator disks skewing

$$
F=F_{1}+F_{2} .
$$

Force and kinematic analysis of the wave generator disks interaction with the flexspline has been performed. The mathematical model is devised for the fixed disks rolling along the free edge of the flexspline, represented in the form of elastic cylindrical shell with the gear ring, the opposite end of which is regarded as absolutely fixed.

Energy losses in the area of the wave generator (11) are proportional to the disks slip velocity $V_{f}$, (10) and are caused by the moments of friction in the zones of the disks contact with the flexspline (4) and (5), turning the disks around in the orthogonal direction to the plane of their motion. The disks turning around and cone-shaped deformation of the flexspline facilitate the formation of some similarity of friction screw pair with the lead angle equivalent to the angle of the disks turn $\gamma$.

Axial fixing of the disks and flexspline impedes their relative helical motion, the axial component of which is transformed into axial slipping of disks relative to the flexspline. This causes severe energy losses in the harmonic 
gear drive. Moments of friction in the zones of the disks contact with the flexspline turn the disks towards «screwing» in the flexspline while axially stretching it by frictional forces, the resultant value of which is equal to double sum of forces $F_{1}$ and $F_{2},(12)$.

For the waveform gear reduction unit of the orepulverizing mill relining drive the axial stretching force $F_{\Sigma}$, acting on the flexspline on the side of the wave generator, at friction ratio $f=0,08$, loading torque $M_{2 \max }=5 \cdot 10^{5} \mathrm{Nm}$, makes $F_{\Sigma L}=12603 \mathrm{~N}$, and for the waveform gear reduction unit of the mixer swing drive, at the same loading, $F_{\sum k}=11619 \mathrm{~N}$.

With the presence of the axial plays, action of the axial frictional forces becomes dangerous not only for the support between the wave generator and the flexspline. The axial forces in disk - flexspline kinematic pairs induce periodic impact loads, vibrations, noise and precipitate wear.

To the aids of reducing axial forces and energy losses in the area of the wave generator may be referred the following ones: production of the intermediate ring of bronze, minimization of the disks skewing angle $\gamma$ through the use of the most rigid bearing assemblies and application of forced lubrication with high antifriction properties.

With similar angles of generating linkages turn $\gamma$, the highest energy losses are incurred by the disk generator since it has maximum length of power contact with the flexspline. The roller generator has less length of such contact, the moment of friction $F_{1}$ and $F_{2}$, turning about the rollers in the orthogonal direction to their motion is lower and the losses are less.

In the cam wave generator, frictional forces $F_{1}$ and $F_{2}$ are exerted simultaneously from two diametrically opposed sides of the cam and produce equal, opposing one another moments of friction being balanced relative to the major axis of the wave generator and minimizing axial forces and friction energy losses.

\section{EXPERIMENTAL INVESTIGATION OF AXIAL FORCES ACTING IN WAVE GENERATOR DISKS AND FLEXSPLINE CONTACT}

During operational life testing of the waveform gear reduction unit of $M P-600 A S$ mobile mixer with the capacity of $6000 \mathrm{kN}$ molten metal, at load $M_{2}=300 \mathrm{kNm}$, breakage of flexspline axial fixing bolts $M 16$ occurred and the wave generator bronze axial fixing journal failed too. Causes of axial forces development and their numerical values leading to failure of the axially-loaded harmonic gear drive parts were unknown. In literary sources, the information on the origin of axial forces developing in harmonic gear drives (Fig. 1 - 8) is not available [9].

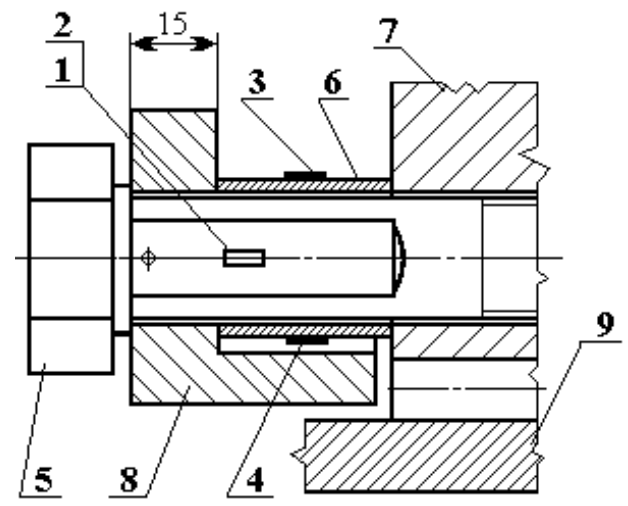

Fig. 1. Diagram of load unit for experimental investigation of axial forces in flexspline: $1,2,3,4$ - resistive-strain sensors; 5 - fixing bolt; 6 flexible sleeve; 7 - hub; 8 - washer; 9 - flexspline

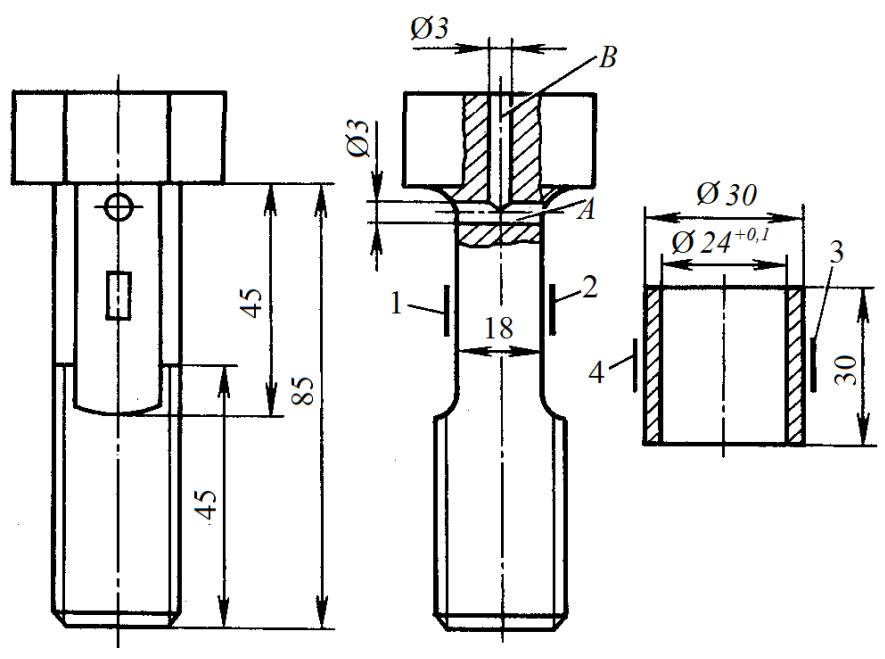

Fig. 2. Strain-gauge bolt and flexible sleeve
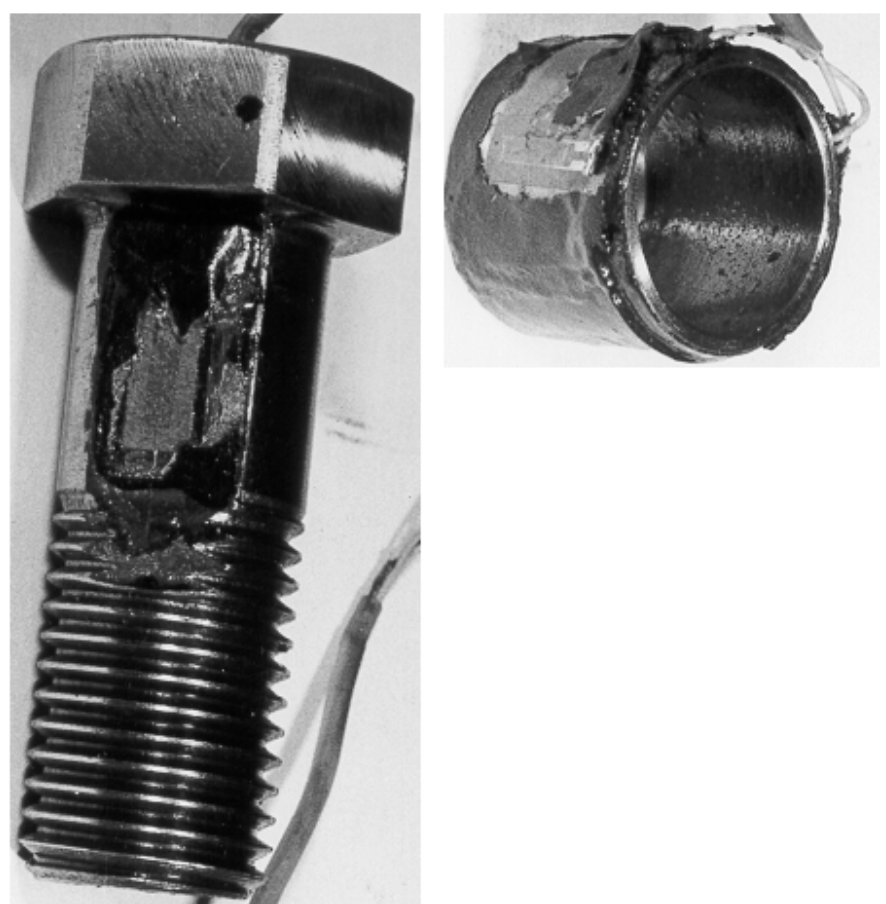

Fig. 3. Strain-gauge bolt and flexible sleeve with resistive-strain sensors 
Experimental investigations were carried out on the harmonic drive unit VZ-1120A of the ore-pulverizing mill and mixer swing harmonic drive unit VZ-1120. In the drive units, a three-disk wave generator is used [10]. The extreme disks are installed in the reversed phase relative to the middle disk and are supported in the input shaft eccentric journals, roller bearings, with minimal axial end clearances.

Axial forces in the flexspline were determined by means of fixing bolts 5 and flexible sleeves 6 strain gauging (Fig. 1) in the wave generator - by means of flexible sleeve 1 strain gauging, to compensate the respective axial forces (Fig. 6) [11].

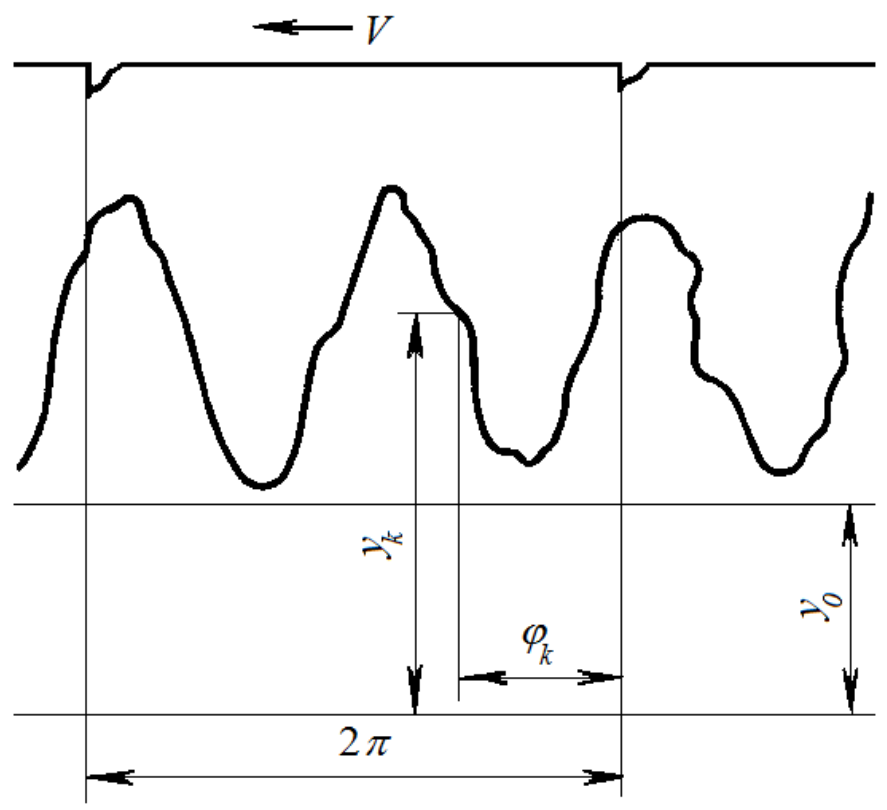

Fig. 4. Oscillogram of strain-gauge bolt load

Experimental investigations of axial forces depending on the wave generator phase of rotation existing in the heavyduty harmonic gear drives with the disk wave generator were carried out at fixed loads of the waveform gear reduction unit $\left(M_{2}=\right.$ const). At fixed load of the waveform gear reduction unit $M_{2}=500 \mathrm{kNm}$, the forces on the fixing bolts and flexible sleeves of the flexspline are shown in Fig. 7, forces on the flexible sleeve of the wave generator are shown in Fig. 8.

In Fig. 9 and Fig. 10 characteristic curves of axial forces measured in the flexspline and gear reduction units VZ-1120A of the ore-pulverizing mill wave generators and gear reduction unit $V Z-1120$ of the mobile mixer vs loading torque $M_{2}$.

The experiments were conducted using the production prototypes of the tilting drive gear reduction units of mobile mixer $M P-600 A S$ with the capacity of $6000 \mathrm{kN}$ hot metal and of relining drive of $M G R 5500 \times 7500$ ore-pulverizing mill with the volume of $160 \mathrm{~m}^{3}$, capacity of the loaded ore $2200 \mathrm{kN}$.

In the waveform gear reduction unit of MGR $5500 \times 7500$ ore-pulverizing mill swing drive the axial forces are higher than in the similar waveform gear reduction unit of $M P$ $600 A S$ mobile mixer swing drive.

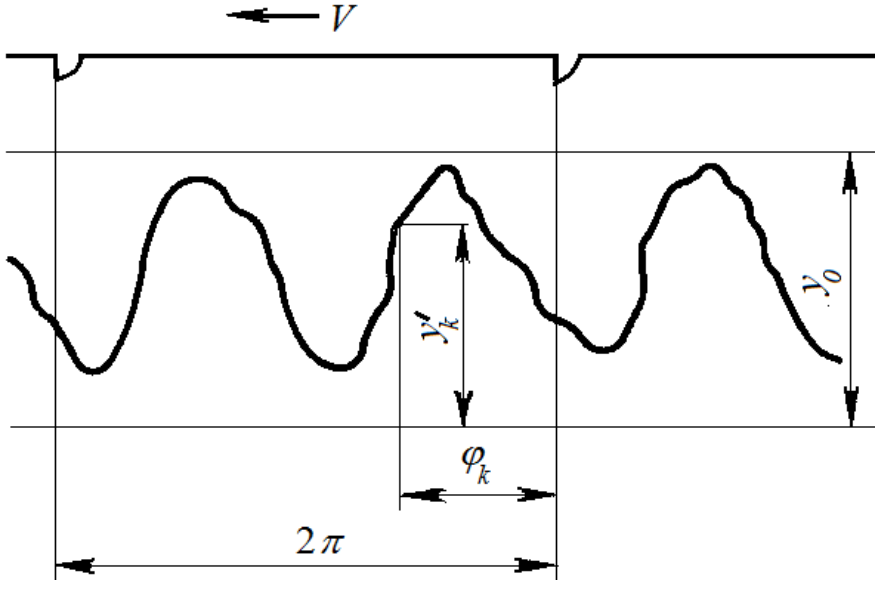

Fig. 5. Oscillogram of flexible sleeves load

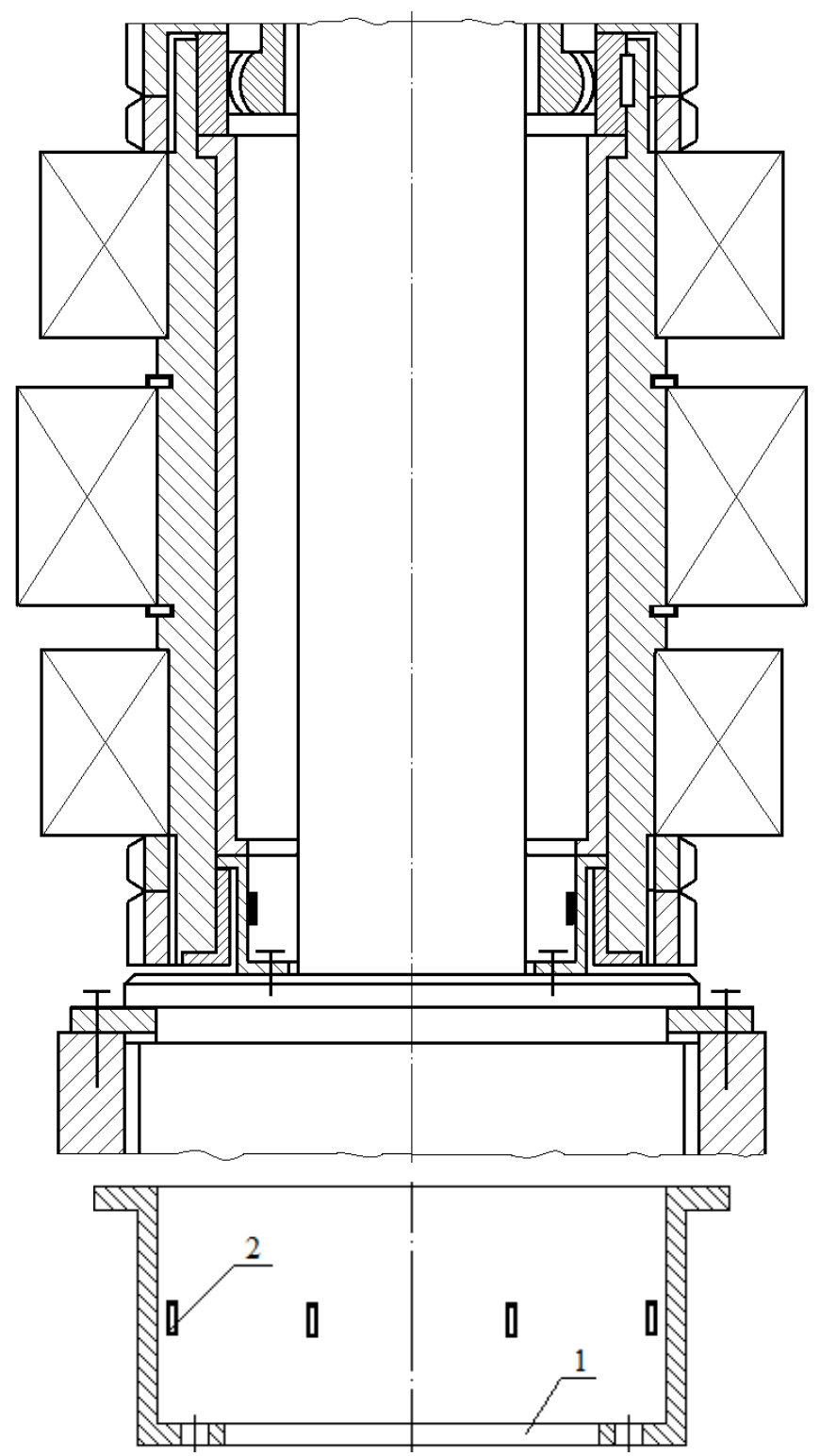

Fig. 6. Structural drawing of measuring axial forces in wave generator: 1 - flexible sleeve; 2 - resistive-strain sensor 


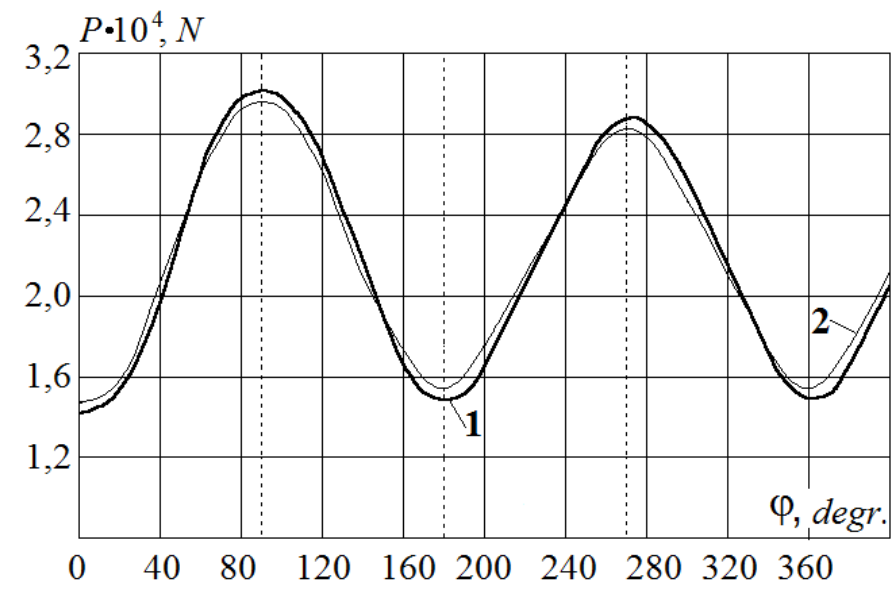

Fig. 7. Axial force versus wave generator angle of rotation $\boldsymbol{\varphi}$, at loading of waveform gear reduction unit $M_{2}=5 \cdot 10^{5} \mathrm{NM}$ on bolt 1 and sleeve 2 of flexspline

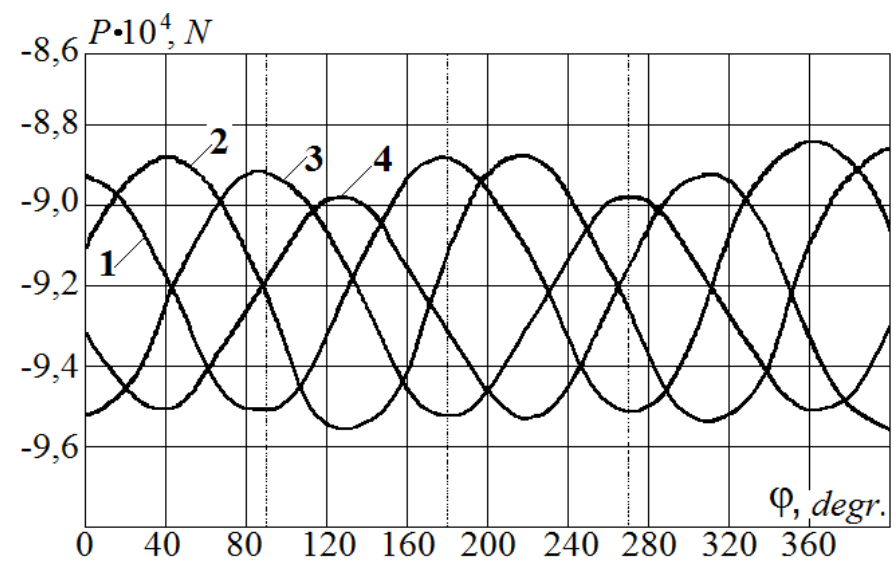

Fig. 8. Axial force versus wave generator angle of rotation $\boldsymbol{\varphi}$, at loading waveform gear reduction unit $\mathrm{M}_{2}=5 \cdot 10^{5} \mathrm{~N}$, on wave generator sleeve in accordance with resistive-strain sensors indications $1-4$

For loading torques $M_{2}=5 \cdot 10^{4} \div 5 \cdot 10^{5} \mathrm{NM}$, axial force on the flexspline of $V Z-1120 A$ waveform gear reduction unit of the ore-pulverizing mill exceeds similar axial force of the mobile mixer $V Z-1120$ waveform gear reduction unit by $9 \div$ $10 \%$. In doing so, axial force on ore-pulverizing mill $\mathrm{VZ}$ $1120 \mathrm{~A}$ swing gear reduction unit wave generator is higher than the same of the mixer by $8 \div 11 \%$.

The available discrepancies in values of axial forces in waveform gear reduction units $V Z-1120 A$ and $V Z-1120$ of $M G R 5500 \times 7500$ ore-pulverizing mill and $M P-600 A S$ mobile mixer drive mechanisms are specified basically by the structural features, geometry-gear ratios relationship of the gear reduction units under investigation. At similar loading torques $M_{2}, V Z-1120 A$ waveform gear reduction unit of the ore-pulverizing mill transmits power by $28 \%$ more than similar VZ-1120 gear reduction unit of the mobile mixer.

Comparative analysis of the results of theoretical and experimental investigations of axial forces on the production prototypes of $V Z-1120 A$ and $V Z-1120$ waveform gear reduction units and of the respective mechanical drives of $M G R 5500 \times$ $\times 7500$ ore-pulverizing mill and $M P-600 A S$ mobile mixer shows some discrepancy of the obtained data not exceeding $6 \%$ through the whole range of measurements that gives evidence of the obtained results reliability.

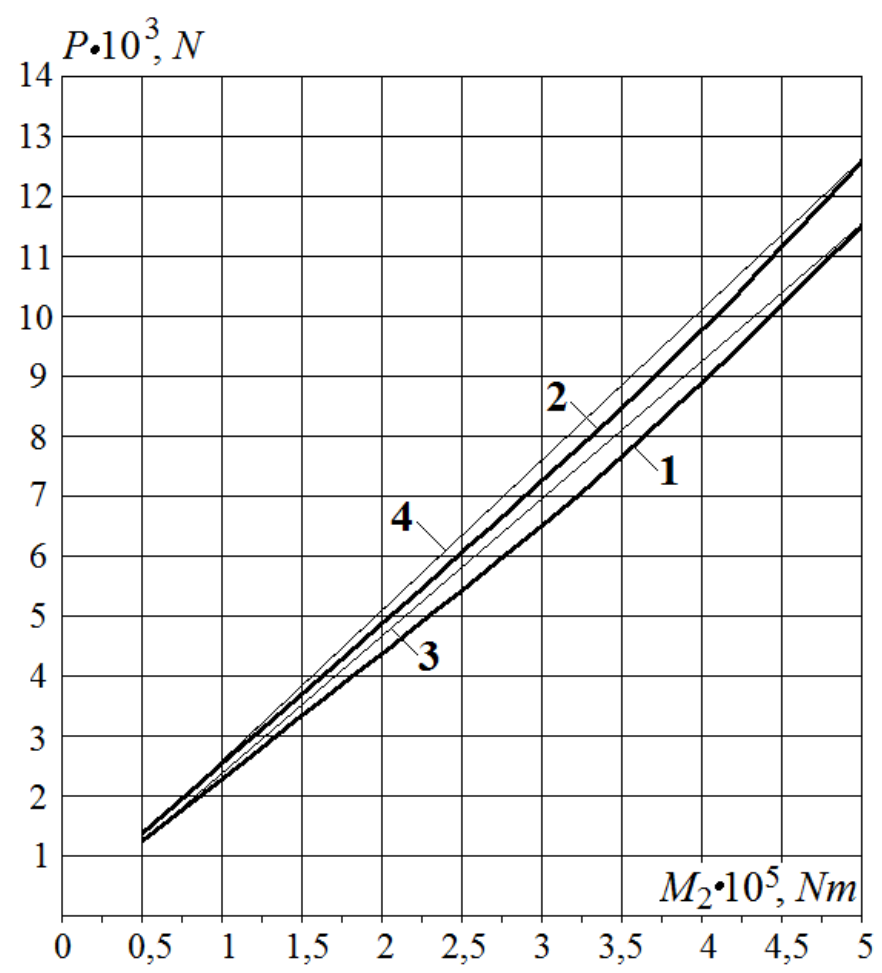

Fig. 9. Axial force $\mathrm{P}$ versus loading torque $M_{2}$ : on flexspline: 1, 3 of $M P$ $600 A S$ mixer drive, and 2, $4-$ of $M G R 5500 \times 7500$ ore-pulverizing mill drive; curves 1,2 are obtained experimentally while curves 3,4 - theoretically

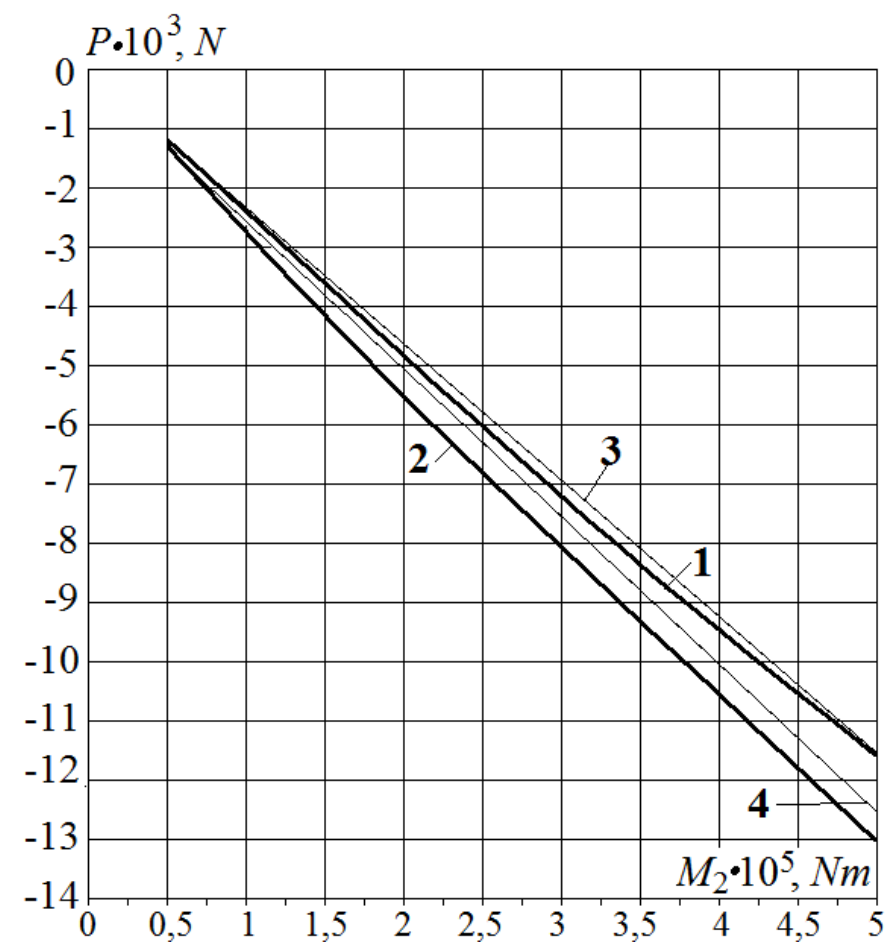

Fig. 10. Axial force $\mathrm{P}$ versus loading torque $M_{2}$ on the wave generator: 1, 3 of $M P-600 A S$ mixer drive, and 2, 4-MGR $5500 \times 7500$ ore-pulverizing mill drive; curves 1,2 are obtained experimentally, curves 3, 4 - theoretically 


\section{CONCLUSION}

For the first time ever the mechanism of interaction between the wave generator disks and the flexspline was revealed and the conditions of energy losses occurrence in the area of the wave generator were determined. Mathematical analog of the mechanical processes proceeding in the zones of the wave generator disks contact with the flexspline was developed.

It is found that axial forces in the harmonic gear drive possess frictional nature. Kinematic pairs: disks - flexspline serve as a source of axial forces in the harmonic gear drive. Strict parallelism of the disks axes with the axis of the harmonic gear drive is not provided. This forms similarity of the friction screw pair: disks - flexspline. The rotation of the input shaft activates helical motion of the wave generator which is «screwed» in the flexspline and develops axial force P, taken up by the flexspline. In the batch-produced harmonic gear drives, axial forces are low and they do not affect their operation while in the heavy-duty harmonic gear drives the axial forces feature greater values and require to be measured and recorded.

In order to reduce axial forces in heavy-duty harmonic gear drives it is recommended to:

- eliminate floating installation of the wave generator by mounting it on the bearing assemblies;

- eliminate spherical bearings for the disks installation;

- eliminate "spinning" of disks relative to the supports;

- remove axial plays in the wave generator and flexspline;

- install a bronze ring in the space between the disks and the flexspline;

- deliver forced lubrication to the zone of the disks contact with the flexspline.

Fulfilment of the above recommendations will allow the disks skews and the axial movements amplitude to be minimized, the axial forces that with the presence of eccentrically installed heavy spinning masses take on the impact nature, to be reduced. Decreasing frictional forces in kinematic pairs «disks - flexspline» reduces axial forces, energy losses and disks wear.

The results of the investigations obtained analytically and using experimental techniques correlate well and are implemented at PJS NKMZ when manufacturing heavy-duty waveform gear reduction units for mining and metallurgical equipment.
Analytical derivations obtained with the use of mathematical models are supported by the results of experimental investigations. Approval of mathematical models analogs of kinematic pairs of higher degree: disk - flexspline, on the waveform gear reduction units of $M G R 5500 \times 7500$ ore-pulverizing mill and $M P-600 A S$ mobile hot-metal mixer has presented satisfactory coincidence of the data obtained experimentally with the results of analytical solution. Discrepancies between the data of theoretical and experimental investigations of axial forces in the waveform gear reduction units of $M G R 5500 \times 7500$ ore-pulverizing mill relining and $M P-600 A S$ mobile mixer swing drives do not exceed $6 \%$, that testifies to high reliability of the results obtained.

The results of the performed investigations make it possible to optimize the parameters of heavy-loaded waveform gear reduction units at the stage of their design that facilitates the enhancement of scientific and technological potential of heavy industry.

\section{References}

[1] V.A. Aleksandrov, G.M. Skudar, V.A. Pankov, V.N. Strelnikov. Harmonic gear drives in heavy engineering and metallurgical engineering industry, Moscow: Mechanical engineering, 1991, $166 \mathrm{p}$.

[2] Huimin Dong, Zhengdu Zhu, Weidong Zhou, Zhi Chen. "Dynamic Simulation of Harmonic Gear Drives Considering Tooth Profiles Parameters Optimization". Journal of Computers, 2012, vol. 7, no. 6, pp. 1429-1436. doi:10.4304/jcp.7.6.1429-1436.

[3] P.S. Gandhi, F.H.Ghorbel. "Closed-loop compensation of kinematic error in harmonic drives for precision control applications". IEEE Transactions on Control Systems Technology, 2002, vol. 10, is. 6, pp. 759-768.

[4] T. Tuttle, W. Seering. "Kinematic Error, Compliance, and Friction in a Harmonic Drive Gear Transmission". Proceedings of ASME Advances in Design Automation, USA, New Mexico, 1993, vol. 65-1, pp. 319324.

[5] S.A. Shuvalov, Yu.M. Parshin. "Loads on a Generator of the Wave Gearing". Izvestiya Vuzov. Mashinostroenie. 1971, vol. 12, pp. 19-23.

[6] John Lewis. "Fast forward for harmonic - drive gearing". Glob. Des. News, vol. № 2, pp. 46-47, April 2000.

[7] Fathi H. Ghorbel, Prasanna S. Gandhi, Friedhelm Alpeter. "On the kinematic error in harmonic drive gears". Trans. ASME. J. Mech. Des. 2001. 123, vol. 1, pp. 90-97.

[8] Hsueh-Chien Hou, Yu-Ren Wu. "Dynamic simulation and analysis of large-scale gear reducers". Advanced materials research, vol. 939, pp. 530-538, 2014.

[9] B.S. Kasatkin, A.B. Kudrin, A.M. Lobanov, V.A. Pivtorak, P.I. Polukhin, N.A. Chichenev. Experimental methods of research of stresses and strains- Kiev: Naukova dumka, 1981. 583 p.

[10] V.L. Gadolin, N.A. Drozdov, V.N. Ivanov, D.N. Reshetov, S.A. Shuvalov. Machines and benches for testing parts, Moscow: Mechanical engineering, 1979, $343 \mathrm{p}$.

[11] I.G. Zedginidze, Experimantal design for the research of multifactor systems, Moscow: Science, 1976, 390 p. 